and UCB, Consultant for: AbbVie, Amgen, BMS, Celgene, Galapagos, Gilead, Janssen, Lilly, Novartis, Pfizer, and UCB, Murray B Urowitz Grant/research support from: GSK, Consultant for: BMS, Celgene, GSK, Lilly, UCB, Zahi Touma Grant/research support from: GSK Canada, Consultant for: UBC, Pfizer, Janssen, Inc

DOI: 10.1136/annrheumdis-2019-eular.1146

\section{THU0689 1 ASTHMA AND ELEVATION OF ANTI-CITRULLINATED PROTEIN ANTIBODIES PRIOR TO THE ONSET OF RHEUMATOID ARTHRITIS}

Alessandra Zaccardelli ${ }^{1}$, Xinyi Liu ${ }^{1}$, Julia Ford ${ }^{1,2}$, Sara Tedeschi ${ }^{1,2}$, Jing Cui $^{1,2}$, Bing Lu ${ }^{1,2}$, Su Chu ${ }^{1,2}$, Peter Schur ${ }^{1,2}$, Cameron Speyer ${ }^{1}$, Karen Costenbader ${ }^{1,2}$, William Robinson ${ }^{3,4}$, Jeremy Sokolove ${ }^{3,4,5}$, Carlos Camargo, Jr. ${ }^{1,2} 6$,

Jeffrey Sparks ${ }^{1,2}$. 'Brigham and Women's Hospital, Boston, United States of America; ${ }^{2}$ Harvard Medical School, Boston, United States of America; ${ }^{3}$ Stanford University School of Medicine, Palo Alto, United States of America; ${ }^{4}$ VA Palo Alto Health Care System, Palo Alto, United States of America; ${ }^{5}$ Abbvie, Redwood City, United States of America; ${ }^{6}$ Massachusetts General Hospital, Boston, United States of America

Background: Anti-citrullinated protein antibodies (ACPA) are central to RA pathogenesis, with serum ACPA titers elevated years prior to clinical RA onset. Aberrant protein citrullination may occur in inflamed airway mucosa, forming neoantigens producing ACPA before articular involvement. Thus, individuals with inflammatory airway diseases, such as asthma, may be susceptible to RA-related autoimmunity.

Objectives: To investigate asthma as a risk factor for ACPA+ in serum prior to clinical RA onset.

Methods: We performed a cross-sectional analysis among women in the Nurses' Health Studies to examine whether asthma was associated with pre-RA ACPA+. Incident RA cases occurring after blood draw met research criteria and were each matched to 3 controls by age and menopausal status. Presence of self-reported asthma and potential confounders, including smoking pack-years, were assessed using questionnaires. The sensitive (primary) definition for ACPA+ was: $>3$ units on CCP2 or elevation ( $>99$ th percentile of the control distribution) on a research assay composed of autoantibodies targeting specific citrullinated protein epitopes. The specific (secondary) definition for ACPA+ was: $>5$ units on CCP2 or elevation of $\geq 2$ different antibodies to citrullinated proteins on the research assay. Logistic regression was used to obtain ORs for ACPA+ independent of confounders. We performed secondary analyses using the specific definition for ACPA+ and in subgroups restricted to never smokers and pre-RA cases.

Results: We measured ACPA on 1,135 women, including 286 pre-RA cases. Serum was banked a mean of 9.7 years (SD 5.8) prior to RA diagnosis, mean age of 51.9 years (SD 7.9). Overall, $12 \%$ of pre-RA cases reported asthma compared to $7 \%$ of controls; pre-RA cases were heavier smokers than controls. Of pre-RA cases, 96 (34\%) were ACPA+ by the sensitive definition and $60(21 \%)$ by the specific definition. Among the entire sample, women with asthma were more likely to have ACPA+ (unadjusted OR 2.51, $95 \% \mathrm{Cl} 1.42-4.44$ ) compared to those without asthma. After adjusting for age, smoking, BMI, and time to RA/matched date, asthma remained significantly associated with ACPA+ (OR 2.32, $95 \% \mathrm{Cl} 1.29-4.16)$. In the secondary analyses, we found similar associations of asthma with ACPA+ when using the specific definition for ACPA + (multivariable OR 2.28, 95\% $\mathrm{Cl} 1.11-4.69$ ) and when restricted to never smokers (OR $3.11,95 \% \mathrm{Cl} 1.29-7.47$ ) and only pre-RA cases (OR 2.22, $95 \% \mathrm{Cl} 1.01-4.88)$

Table: Odds ratios for elevated $\mathrm{ACPA}^{*}$ by asthma status at time of blood draw.

\begin{tabular}{|c|c|c|}
\hline & $\begin{array}{l}\text { Unadjusted } \\
\text { OR }(95 \% \mathrm{Cl})\end{array}$ & $\begin{array}{c}\text { Multivariable }{ }^{\star \star} \\
\text { OR }(95 \% \mathrm{Cl})\end{array}$ \\
\hline \multicolumn{3}{|c|}{ Entire sample $(n=1,135)$} \\
\hline No asthma & 1.00 (Ref) & 1.00 (Ref) \\
\hline Asthma & $2.51(1.42-4.44)$ & $2.32(1.29-4.16)$ \\
\hline \multicolumn{3}{|c|}{ Never smoker subset $(n=573)$} \\
\hline No asthma & 1.00 (Ref) & 1.00 (Ref) \\
\hline Asthma & $3.19(1.37-7.39)$ & $3.11(1.29-7.47)$ \\
\hline \multicolumn{3}{|c|}{ Pre-RA case-only subset $(n=286)$} \\
\hline No asthma & 1.00 (Ref) & 1.00 (Ref) \\
\hline Asthma & $2.34(1.13-4.87)$ & $2.22(1.01-4.88)$ \\
\hline
\end{tabular}

${ }^{*}$ ACPA positivity (sensitive version) was defined as $>3$ units on the commercial CCP2 assay or $>99$ th percentile of control distribution on the research ACPA assay.

**Adjusted for age at blood draw, time to RA diagnosis/matched date for controls, BMI,

smoking pack-years (continuous, pack-years)

Conclusion: Asthma may be a novel risk factor for elevation of ACPA prior to RA onset, independent of smoking. These findings encourage further research on the contribution of airway inflammation to RA pathogenesis.

Disclosure of Interests: : Alessandra Zaccardelli: None declared, Xinyi Liu: None declared, Julia Ford: None declared, Sara Tedeschi: None declared, Jing Cui: None declared, Bing Lu: None declared, Su Chu: None declared, Peter Schur: None declared, Cameron Speyer: None declared, Karen Costenbader: None declared, William Robinson: None declared, Jeremy Sokolove Shareholder of: AbbVie, Employee of: AbbVie Carlos Camargo, Jr.: None declared, Jeffrey Sparks Grant/research support from: Bristol-Myers Squibb, Amgen, Consultant for: Optum DOI: 10.1136/annrheumdis-2019-eular.3107

\title{
THU0690 DISEASE ACTIVITY CORRELATES WITH INSULIN RESISTANCE AND ADIPOCYTOKINES IN PATIENTS WITH DMARD-NAÏVE RHEUMATOID ARTHRITIS
}

ali taylan ${ }^{1}$, Burak Toprak ${ }^{2}$, Baris Akinci ${ }^{3}$, Merih Birlik ${ }^{4}$, Fatma Demet Arslan², Baris Gundogdu ${ }^{5}$, Ayfer Colak ${ }^{2}{ }^{1}$ SBU Tepecik Egitim ve Arastirma Hastanesi, Rheumatology, izmir, Turkey, ${ }^{2} S B U$ Tepecik Egitim ve Arastirma Hastanesi, izmir, Turkey, ${ }^{3}$ Dokuz Eylul University School of Medicine, Department of Internal Medicine, Endocrinology, izmir, Turkey; ${ }^{4}$ Dokuz Eylul University School of Medicine, Department of Internal Medicine, Rheumatology, izmir, Turkey; ${ }^{5}$ Medeniyet University Department of Internal Medicine, Rheumatology, istanbul, Turkey

Background: Cardiovascular events such as myocardial infarction and stroke are frequent comorbidities in rheumatic diseases [1]. In relation, components of the metabolic syndrome (MS) including insulin resistance (IR), central obesity, high blood pressure, high triglycerides, and low highdensity lipoprotein (HDL) are related to a high rate of endothelial dysfunction and atherosclerosis in patients with RA [2]

Objectives: We aimed to investigate the relationship between disease activity and insulin resistance (IR) and the levels of adipocytokines in non-diabetic patients with newly diagnosed rheumatoid arthritis (RA) who are naïve to disease modifying anti-rheumatic drugs (DMARDs).

Methods: Forty-seven DMARD-naïve patients with RA and 25 age-, gender-, and BMI-matched controls were included. Erythrocyte sedimentation rate (ESR), C-reactive protein (CRP), 28-joint-count disease activity score (DAS28), serum lipids, glucose, HbA1c, insulin, leptin, resistin, visfatin, and RBP4 levels were measured. Homeostasis model assessment for insulin resistance (HOMA-IR) was calculated. Patients were studied before and 3 months after treatment with DMARDs.

Results: Levels of adipokines were similar in patients with RA and controls $(p>0.05$ for all). However, RA patients with active disease (DAS28 $>3.2)$ had numerically higher levels of leptin $(9.3(3.7-17.4)$ vs. 7.6 (3.7$11.0), p=0.289)$, insulin (8.0 (5.2-12.7) vs. 5.9 (4.2-8.7), $p=0.285)$, and HOMA-IR (1.9 (1.1-3.0) vs. $1.3(1.0-1.9), p=0.209)$. DAS28 was correlated with HOMA-IR $(r=0.356, p=0.016)$, insulin $(r=0.323, p=$ $0.02)$, and leptin $(r=0.399, p=0.005)$ in the study group (Figure-1) Regardless of the type of treatment modality, leptin levels (7.4 (4.4-13.4) vs. 6.4 (3.3-11.6, $\mathrm{p}=0.047)$ decreased significantly after treatment, as did insulin levels $(6.9(4.9-12.5)$ vs. $5.9(4.1-8.8), p=0.01)$ and HOMA IR score $(1.7(1.1-2.7)$ vs. $1.3(1.0-2.0), p=0.012)$. The reduction in leptin was more prominent in patients with active disease $(9.3$ (3.7-17.4) vs 6.9 (3.1-11.4), $\mathrm{p}=0.028)$. The reduction in ESR was correlated with $\triangle$ HOMA-IR $(r=0.308, p=0.039)$, and CRP reduction was correlated with $\Delta$ resistin $(r=0.288, p=0.049)$ and $\triangle R B P 4(r=0.456, p=0.001)$. Conclusion: Disease activity is associated with IR and correlates with circulating levels of adipokines in patients with RA. Treatment with DMARDs reduces leptin and improves IR.

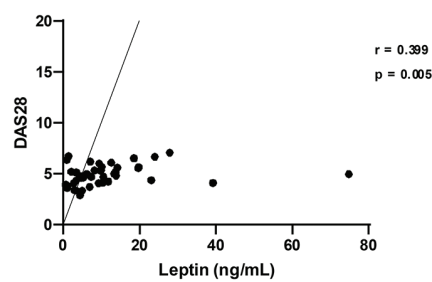

